\title{
Hemşire çizelgeleme problemi ve bir sağlık kuruluşunda uygulama
}

\author{
Merve ARSLAN ${ }^{1, *}$, Burcu ÖZCAN ${ }^{1}$ \\ ${ }^{1}$ Kocaeli Üniversitesi Müh. Fak. Endüstri Müh. Bölümü, Umuttepe yerleşkesi, Kocaeli.
}

Geliş Tarihi (Received Date): 03.06.2021

Kabul Tarihi (Accepted Date): 29.11.2021

\section{$\ddot{\mathbf{O} z}$}

Sağlık kuruluşlarında görev yapan kişiler ă̆ır, yorucu çalışma koşullarında çalışmaktadırlar. Günümüzde pandeminin etkisi ile çalışma şartları daha da zorlaşmıştır. Bu sebeple çalışanların istek, önerileri dikkate alınarak ve yasal koşullar sağlanarak verimli çalışma planları oluşturulması büyük önem taşımaktadır. Çalışma planları gerçekleştirilirken sağlık hizmetinin gecikmeye uğramaması gerekmektedir. Gerçekleştirilen çalışma bir sağllk kuruluşunun filyasyon ekibinde çalışan hemşirelere uygulanmıştır. Yasal kısıtlar, çalışanların memnuniyeti, çalışan istek ve önerileri göz önünde bulundurularak aylık olarak bir nöbet çizelgesi oluşturulmak istenmektedir. Optimum bir çalışma çizelgesi oluşturulması için hedef programlama modeli geliştirilmiştir. Bu oluşturulan matematiksel model ile hemşirelerin çalışma zamanları eşit, dengeli ve adil olacak şekilde atama yapılması amaç olarak belirlenmiştir. Oluşturulan matematiksel model GAMS 33.2.0 paket programının CPLEX çözücüsü ile çözülüp bir aylık optimum hemşire nöbet çizelgesi oluşturulmuştur. Bu nöbet çizelgesinde yasal koşullar, hemşirelerin istek ve önerilerine dikkat edilerek oluşturulmuştur. Böylece nöbet ve izin günlerinin eşit, adil olmast sağlamıştır.

Anahtar kelimeler: Hemşire çizelgeleme problemi, hedef programlama, optimizasyon.

\section{Nurse scheduling problem and application in a healthcare organization}

\begin{abstract}
People working in health institutions work in heavy and tiring working conditions. Today, working conditions have become more difficult with the effect of the pandemic.

\footnotetext{
*Merve ARSLAN, merve.arslan1396@gmail.com, https://orcid.org/0000-0002-8873-4732

Burcu ÖZCAN, burcu.ozcan@kocaeli.edu.tr, http://orcid.org/0000-0003-0820-4238
} 
For this reason, it is of great importance to create efficient work plans by taking into account the wishes and suggestions of the employees and by providing the legal conditions. Health services should not be delayed while working plans are being carried out. The study was applied to the nurses working in the filiation team of a health institution. It is desired to create a shift schedule on a monthly basis, taking into account legal restrictions, employee satisfaction, employee requests and suggestions. A goal programming model has been developed to create an optimal work schedule. With this mathematical model, it was determined as the aim to assign nurses in a way that their working time would be equal, balanced and fair. The mathematical model created was solved with the CPLEX solver of the GAMS 33.2.0 package program and a onemonth optimum nurse shift schedule was created. And in this shift schedule, the legal conditions were created by paying attention to the wishes and suggestions of the nurses. Thus, it was ensured that the days of duty and leave were equal and fair.

Keywords: Nurse scheduling problem, goal programming, optimization.

\section{Giriş}

Çizelgeleme elde var olan sınırlı olanakları (zaman, çalışan, ekipman vb.) optimum şekilde kullanılarak, yapılacak işlerin belli kurallar ve performans seçenekleri dikkate alınarak nerede, nasıl ne zaman ne kadar sürede yapılacağını belirlemede kullanılan sıralama, dizme işlemi olarak tanımlanabilir [1].

Çizelgeleme planlanan zamanda, planlanan yerde müşteri istek ve önerileri doğrultusunda hızlı, etkin olacak şekilde en iyi hizmeti müşteri veya kullanıcılara ulaştırmayı amaçlamaktadır [2]. Çizelgeleme üretim ve hizmet sistemlerinde bulunan işlerin sırasını düzenlemede kullanılır. Üretim ve hizmet proseslerinde var olan kısıtlı kaynakların en iyi şekilde faydalanılmasını hedeflemektedir. Yapılması gereken işler veya görevler ilgili ekipmanlara uygun şekilde atanır. Bu atama ile işlerin hangi sırayla yapılacağı ve hangi makinelerde işlem görecekleri belirlenmiş olur. Sonuç olarak müşteri bekleme zamanı ve envanter miktarı azalmış, müşteri memnuniyeti sağlanmış, personel ve eldeki ekipman verimli şekilde kullanılmış olur [3].

Günümüzde pandemi şartlarının de etkisi ile hizmet sistemlerinde çizelgelemenin önemi oldukça artmıştır. Çizelgeleme türlerinden biri olan iş gücü çizelgeleme hizmet sektöründe gün geçtikçe daha önemli ve daha maliyetli bir hal almaya başlamıştır. İş gücü çizelgeleme çalışanın talebine ve iş kanuna uygun olarak oluşturulan bir çalışma planıdır. Çalışan performansı ve memnuniyeti optimum seviyeye ulaştırılmak amaçlanmıştır.

Hizmet sektörlerinin çalışma koşulları çok çeşitlidir. Bu sebeple çizelgeleme modelleri ve çözüm teknikleri oldukça fazla ve çeşitlidir. Hizmet sektörü olarak hastane ve sağlık sistemlerinde karşımıza çıkan en çok ve en önemli problem hemşire çizelgeleme problemidir. Hemşire çizelgeleme hemşireler için hastanenin kapasite ve kısıtlarını dikkate alarak personel planlama işlemidir.

Belirlenen hemşire çizelgesine göre her vardiyaya veya nöbete hemşire atanır. İşgücü maliyeti hizmet sektöründe en büyük gider olduğu için, hastanelerin personelleri doğru görevlere ataması, hastanenin planlamasının hazırlanmasında en önemli roldür. 
Hemşire çizelgeleme problemi doğrusal olmayan maliyet fonksiyonuna sahip olduğundan görev hemşire eşleştirmesi çok sayıda olduğu için çözümü zor problemdir. Amaç mevcut hemşirelerin dengeli dağılımını sağlayarak sağlık kuruluşunun maliyetini azaltmaktır.

Çok amaçlı problemlerin çözümünde doğrusal programlama bazı zamanlarda yetersiz kalmaktadır. Siklıkla kullanılan çoklu karar verme kriterlerinden hedef programlama modeli amaç fonksiyonunu maksimize ya da minimize etmek yerine, var olan kısıtlar eşliğinde, belirlenen hedeflerden sapma miktarlarını minimize eder. Bu sapmalar artı ve eksi sapmalar olarak iki şekilde ele alınır [4]. Hedef programlama özellikle personel çizelgeleme gibi karmaşık problemlerin çözümünde kullanılır.

Bu çalışmada, çalışma ve yasal kısıtlar dikkate alınmıştır. Sağlık kuruluşundaki personel planlama sürecinde yer alan hemşire görev çizelgeleme probleminin çözümü için hedef programlama ile matematiksel model geliştirilmiştir. $\mathrm{Bu}$ model GAMS/CPLEX programında çözülmüştür.

$\mathrm{Bu}$ çalışma beş bölümden oluşmaktadır. İlk bölümde çizelgeleme ve hemşire çizelgeleme konusundan bahsedilmiştir. İkinci bölümünde literatürde hemşire çizelgeleme ile alakalı çalışmalar detaylı taranmıştır ve özet tablo oluşturulmuştur. Üçüncü bölümde hemşire çizelgeleme probleminin tanıtımı, problemin çözümü için geliştirilen yöntemler ve önerilen matematiksel programlama model ile ilgili detaylardan bahsedilmiştir. Dördüncü bölümde hemşire çizelgeleme probleminin çözümünden bahsedilmiş olup nöbet listesi oluşturulmuştur. Beşinci bölümde yapılan uygulama anlatılmış ve çalışmanın sonuçları değerlendirilip tartışılmıştır.

\section{Literatür incelemesi}

Hemşire çizelgeleme problemi iş gücü planlamada önemli bir aşamadır. Hemşireler için belirlenen plan vakti içerisinde çizelge oluşturulur. $\mathrm{Bu}$ çizelgede görevler, izin, dinlenme süreleri ile ilgili listeler bulunur. $\mathrm{Bu}$ listeler devletin çalışma politikalarına ilişsin sınırlamalar dikkate alınarak haftalık veya aylık olarak yapılır. Bu sayede hemşire çizelgelemede ile hazırlanan görevler her günü içerecek şekilde her hemşireye görevler sırasıyla atanır. Bu çalışmanın amacı çalışan performansını ve memnuniyetini maksimize edip oluşan maliyetleri minimize etmektir.

Çalışma kapsamında, literatürde hemşire çizelgeleme problemine ait son zamanlarda gerçekleştirilen çalışmalar detaylı olarak taranmıştır. Taranan bu çalışmaların modelleme amacı, çözüm yaklaşımı, kısıtlar, amaç fonksiyonları, çizelgeleme çeşitleri incelenmiştir. Bu bilgiler ayrıntılı olarak şekilde açıklanıp Tablo 1'de kronolojik sıra ile özetlenmiştir.

Güngör [5], çalışmasında hemşire maliyetlerini düşürmeyi hedeflemiştir. Bu yüzden hemşire çizelgeleme ve görevlendirme sorununu ele almış olup iki adımlı 0-1 tam sayılı programlama modeli kurmuştur. Birinci adımda iş zamanlarında görevlendirilecek hemşirelerin sayısının bulunması, ikinci adımda hemşirelerin 2 haftalık çalışma çizelgesinin oluşturulması hedeflenmiştir. Azaiez ve Al Sharif [6], çalışmalarında sağlık kuruluşlarından biri olan hastanenin çalışma şartları ve hemşirelerin istekleri 
dikkate alınarak bir model oluşurmuşlardır. Oluşturulan bu model tam sayılı programlama ile kurulmuş olup ILOG/CPLEX programı ile çözülmüş̧ür.

Bard ve Purnomo [7], çalışmalarında hemşire çizelgeleme problemini kolon türetme yöntemini kullanarak çok amaçlı bir hemşire çizelgeleme problemini çözmeyi önermişlerdir. Bu metotta tam sayılı programlama modeli ile kolon türetme yaklaşımını birlikte kullanılmıştır. Karar verme basamağında zit durum oluşturan durumlar nedeniyle yeni metotlar geliştirilmiştir. Trilling vd. [8], hemşire çizelgeleme problemini tam sayılı lineer programlama ile modellemişlerdir. Sonuç olarak adil ve dengeli çizelge oluşturmak için tam sayılı lineer programlama modelinin doğru ve tutarlı netice verdiğini gözlemlemişlerdir.

Wright vd. [9], çalışmasında hemşire çizelgeleme problemini incelemiştir. Hastane politikaları ve yasal kısıtlar kapsamında maliyetleri en azlamayı hedefleyen tam sayılı programlama modeli önermişlerdir. Çivril [10], çalışmasında hemşire çizelgeleme problemini genetik algoritma ile modellemiştir. Model C\# programlama geliştirilmiştir. Geliştirilen algoritma ile aylık hemşire çizelgesinin optimum biçimde hazırlanabileceği gösterilmiştir.

Maenhout ve Vanhoucke [11], çalışmasında hemşirelerin çizelgeleme sorununu evrimsel algoritmayı kullanarak modellemiştir. Hemşire ve hasta memnuniyetini arttırmayı ve maliyetleri en azlamaya amaçlamıştır. Atmaca vd. [12], çalışmalarında sağlık sektöründe hastane verimliliğini arttırmak ve maliyetleri en azlamak için her vardiyada çalışacak olan hemşire sayısı tespit edilmiştir. Sonrasında elde edilen veriler ile adil ve dengeli çizelge oluşturulmak için 0-1 tam sayılı hedef programlama modeli kurulmuştur. Oluşturulan model GAMS programı ile çözüme ulaştırılmıştır.

Bağ vd. [13], hemşire çizelgeleme problemi adil ve dengeli olması için amaçları analitik ağ süreci ile ağırlıklandırılmıştır. Model de hemşireleri olumsuz etkileyen etkenler dikkate alınarak 0-1 tam sayılı programlama ile kurulmuştur. Burke vd. [14] çalışmalarında Pareto analizini de sisteme dahil etmişlerdir. Çalışanlar yasal zorunlulukları sağladıkları bu çizelge sezgisel yöntem geliştirilmiştir. Oluşan talepleri, hızlı çözüm tabanlı gıcırtılı tekerlek optimizasyonu yönteminden faydalanılmıştır ve sonra en iyi çözüm elde etmek için onarıcı çözümü uygulamışlardır.

Büyüközkan [15], çalışmasında hemşire çizelgeleme problemini ele alırken hemşirelerin fiziksel ve psikolojik açıdan ağır koşullar altında çalıştıklarını değerlendirmiştir. $\mathrm{Bu}$ problemin çözümü için Arı Kolonisi Algoritması (AKA) ile 2 model oluşturulmuştur. $\mathrm{Bu}$ iki model Visual Studio $\mathrm{C \#}$ programlama dili kullanılarak çözümlenmiştir. Constantino vd. [16], yaptıkları çalışmalarında hemşire çizelgeleme problemini hemşire istek ve önerileri dikkate alınarak ele almışlardır. Görev atama prosesine dayalı sezgisel yöntem ile model kurulmuştur.

Öztürkoğlu ve Çalışkan [17], çalışmalarında hemşire istek ve önerilerini dikkate alarak hemşirelerin mesaiye başlangıç saatlerinde esneklik durumu getiren tam sayılı programlama modeli geliştirmişlerdir. Kim vd. [18], çalışmalarında genetik algoritma aracığıyla hemşire çizelgeleme probleminin olurlu çözüm ihtimalini çoğaltarak kısıtları tahmin edebilecek bir model kurulmuştur ve sonuç olarak seri ve kaliteli çizelgeler oluşturmayı başarmışlardır. 
Wang vd. [19], çalışmasında hemşire çizelgeleme problemini ele alırken hemşire istek ve önerilerini de göz önünde bulundurmuştur. Adil bir çizelgeleme oluşturulmasını hedefleyen 0-1 tam sayılı hedef programlama modeli çalışılmıştır. Oluşturulan bu modelde çalışma vardiyaları derlenerek dengesizlikler ortadan kaldırılıp minimum maliyet hedeflenmiştir. Legrain vd. [20] çalışmalarında iki hemşire takımının çizelgeleme problemi ele alınmıştır. Manuel çizelgeleme durumunu elimine ederek sistemi optimize etmişlerdir. Sezgisel bir yöntemle model kurulup çözümlenmiştir.

Agyei vd. [21], çalışmalarında hemşire çizelgeleme problemini incelemişlerdir. Hemşirelerin istekleri ve önerileri göz önünde bulundurularak model geliştirilmiştir. Hemşirelerin iş yükü dağılımının dengelenmesi hedeflenmiştir ve bu duruma uygun 0-1 tam sayılı hedef programlama modeli önerilmiştir. Lin vd. [22], çalışmasında hemşire çizelgeleme problemine değinirken hemşirelerin istek ve görüşlerini dikkate almıştır. Hemşirelerin memnuniyetini optimize etmek için genetik algoritma temelli bir memetik algoritma önerilmiştir.

Küçük [23], çalışmasında hemşire çizelgeleme manuel yapılırken 6-8 saat sürdüğünü gözlemlemiştir. Bu süreyi minimize etmek amaciyla hemşire çizelgeleme sorununu genetik algoritma ile modellemiştir. Hemşirelerin çalışma saatlerini optimum düzeye getirmek için modelin çözümünde MATLAB programı kullanılmıştır. Thongsanit vd. [24], çalışmalarında hemşireleri tecrübelerine göre sınıflandırmıştır ve dengeli iş yükü dağılımı sağlayarak vardiyalara hemşire ataması gerçekleştirmek için hedef programlama modeli geliştirmiştir.

Karayel ve Atmaca [25], çalışmalarında özel hastanede hemşire çizelgeleme problemi incelemişlerdir. Hastaların memnuniyet düzeyini arttırıp, hemşirelere dengeli ve maliyetleri azaltan bir çizelge oluşturmak amaciyla 0-1 tam sayılı matematiksel programlama modeli geliştirmişlerdir. Eren vd. [26], çalışmasında hemşirelerin verilen hizmeti en doğru biçimde gerçekleştirebilmeleri için vardiyaların adil ve dengeli olması gerektiğine değinmiştir. Çalışmanın yapıldığı hastanede 4 vardiya bulunmaktadır ve bu vardiyalara eşit bir atama işlemi gerçekleşmesi için hedef programlama modeli geliştirilmiştir. Model ILOG CPLEX Optimizasyon programından faydalanılmıştır.

Varlı vd. [27], çalışmalarında hemşirelerin öneri ve isteklerini dikkate alarak çalışma gerçekleştirmişlerdir. Aylık olarak düzenlenen mesai çizelgelerinin optimum şekilde düzenlenmesi için hedef programlama modeli geliştirilmiştir. Geliştirilen model ile adil ve dengeli dağılım sağlanmıştır. Geliştirilen matematiksel model ILOG CPLEX Optimization programıla sonuca ulaştırılmıştır. Geçici ve Güler [28], çalışmalarında hastanenin Kardiyovasküler Cerrahi servisinde çalışan hemşireler çizelgelenme sorununa değinmişlerdir. $\mathrm{Bu}$ problemi karma tam sayılı programlama yöntemiyle modelleyip karar destek sistemine aktarılmıştır. Böylece görevli hemşire için optimum, adil, dengeli iş çizelgeleri oluşturulması sağlanmıştır.

Bayraktar [29], çalışmasında sağlık sektöründe hemşire çizelgeleme probleminin hizmet seviyesini etkilediğine değinmiştir. Hastaların ve hemşirelerin memnuniyet duygularını arttırıp adaletli ve dengeli iş yükünü sağlamayı amaçlamıştır. Çizelgeyi oluşturmaya yönelik tam sayılı hedef programlama modeli önerilmiştir ve GAMS programı ile çözülmüştür. Karakoç ve Küçük [30], gerçekleştirdikleri çalışmada hemşire çizelgeleme probleminin sağlık hizmetlerinin toplum ve kişiler için belirledikleri amaçlara uygun bir şekilde düzenlenmesi gerektiğine değinmişlerdir. Bir devlet 
hastanesinin belirlenen servisinden hemşirelerin çalışma prosesleri ile alakalı bilgiler elde edilmiştir. $\mathrm{Bu}$ bilgiler ile kısıtlar oluşturulmuş olup uygun görevlere uygun hemşirenin atanma işlemini sağlamak için sezgisel algoritma olan Genetik Algoritma ile problem modellenmiştir. MATLAB programı ile problemin optimum çözümü elde edilmiştir. Yani hemşirelerin doğru çalışma saatine optimum bir şekilde atanma işlemi sağlanmıştır.

Karpuz ve Batun [31], özel sağlık kuruluşunda yaptıkları çalışmalarında hemşirelerin iş süreçlerinin planlanmasının dört ana kısımdan oluştuğunu tespit etmişlerdir. Bu kısımlar maaş planı, çizelgeleme, çizelgelerin revize edilmesi, iş zamanlarına çalışanların atanması şeklindedir. Bu çalışmada aniden değişen şartlara uyum sağlayacak iki aşamalı stokastik tam sayılı programlama modeli kurulup çözümlenmiştir. Ve bu tür belirsiz durumlar altında bu stokastik modelleme yöntemiyle oluşturulan çizelgelerin daha gerçekçi ve verimli olduğu görülmüştür. Taş ve Çevik [32], çalışmalarında hemşire çizelgelemenin el ile yapıldığında çok zahmetli ve zaman alıcı bir iş olduğunu gözlemlemişlerdir. Vardiyaların çizelgelenmesi tüm günü kapsayan bir işlem olduğundan koşullar ve kısıtlar oldukça fazladır. Bundan dolayı problem sezgisel algoritmalardan biri olan genetik algoritma ile modellenip PYTHON ile çözüme kavuşturulmuştur.

Ala [33], çalışmasında bir aylık hemşire çizelgesi oluşturmak istemiştir. Bunun için hemşire çizelgeleme problemini arı kolonisi algoritmasını ve genetik algoritmayı kullanarak ayrı ayrı modellemiştir. Her iki modelleme için sonuçlar kıyaslamıştır ve arı koloni optimizasyonunun keşif kabiliyetinin daha yüksek olduğunu göstermiştir. Ayrıca süre olarak genetik algoritma problemin çözümünü daha hızlı yaptığg sonucuna ulaşıldığını gözlemlemişlerdir. Keskin vd. [34] çalışmalarında hemşirelerin çalışma koşullarının zorluğunun çalışma performansını etkilediğine değinmişlerdir. $\mathrm{Bu}$ çalışmada gece gündüz vardiyaların eşit dağıtılmasına özen gösterilmiştir. Problem karma tam sayılı doğrusal programlama ile modellenmiş olup C\#'ın GUROBİ çözücüsü ile çözüm elde edilmiştir. Adil iş dağılımı sağlanmıştır.

Uslu vd. [35] çalışmalarında birçok sektörde müşteri memnuniyetinde azalma olduğunu tespit etmişlerdir. Bu durumu düzeltmek isteyen işverenler önce çalışan memnuniyetini sağlayarak sorunu çözebileceklerini fark etmişlerdir. Bundan dolayı insan fizyolojisine ve psikolojisine uygun ergonomik çalışma zamanları oluşturmak istemişlerdir. $\mathrm{Bu}$ çalışma bir devlet hastanesini acil servisinde çalışan hemşireler nöbet çizelgesi oluşturulmak istenmiştir. Çizelgeleme probleminde model 0-1 tam sayılı programlama ile modellenip hemşire istek ve önerilerini dikkate alan adil çalışma çizelgesi oluşturulmuştur. Eren vd. [36] çalışmalarında 24 saat hizmet sağlayan bir sağlık kuruluşunda hemşirelerin istek ve önerilerini dikkate alarak 1 aylık çalışma planı hazırlamayı hedeflemişlerdir. Hemşirelerin bilgili oldukları yerlerde daha çok çalışmalarını sağlayan çizelge oluşturulmak istenmiştir. Problemin kısıt ve amaçları hedef programlama ile modellenmiştir. Oluşturulan model ILOG/CPLEX programı ile çözümlenmiş olup en iyi çizelge oluşturulmuştur.

Koç [37], çalışmasında hemşirelerin insan sağlığı ile alakalı işler yaptıkları için hemşire çizelgeleme probleminin önemli konu olduğuna değinmiştir. Çalışma tavlama benzetimi algoritması kullanılarak modellenmiştir. Oluşturulan model MATLAB programında kodlanan problem çözülmüştür. El Adoly vd. [38] yaptıkları çalışmada hastanedeki hemşire ihtiyacını optimum seviyede tutmayı ve maliyeti minimize etmek 
istemişlerdir. Yasal koşullar, hastane standartları ve hemşire isteklerine göre problem çoklu emtia ağ akışı ile modellenmiş olup GUROBİ programı ile problem çözülerek optimum çizelge oluşturulmuştur.

Yapılan literatür araştırması sonucunda çıkarımlardan şöyle bahsedilebilir: hemşire çizelgeleme problemi kompleks yapılı ve çok amaçlı bir problemdir. Çok amaçlı problemlerin çözümünde doğrusal programlama bazı zamanlarda yetersiz kalmaktadır. Her sağlık kuruluşunun kısıtları birbirinden çok farklıdır. Bu yüzden literatürde birçok çalışma mevcuttur. Literatür tarandığında bu tür problemlerin çözümü için tam sayılı programlama ile hedef programlama tercih edilmiştir. Hedef programlama personel çizelgeleme gibi karmaşık problemin çoğunda kullanılan bir yöntem olduğu tespit edilmiştir. Ayrıca sağlık kuruluşlarında pandemi dönemi ile ortaya çıkan filyasyon ekibinde vaka artışları çalışan hemşirelerin iş yükü arttırmaktadır ve pandemi şartlarının kısıtları da göz önüne alınarak problem çözülmüştür. Bu sebeplerden dolayı sağlık sektöründe hedef programlama üzerine çalışma yapmak uygun görülmüştür.

Tablo 1. Literatür taraması

\begin{tabular}{|c|c|c|c|c|c|}
\hline Yazar & Yöntem & Çözücü & Yazar & Yöntem & Çözücü \\
\hline $\begin{array}{l}\text { Güngör } \\
(2002)\end{array}$ & $\begin{array}{l}\text { 0-1 tam sayıl1 } \\
\text { programlama }\end{array}$ & LINNDO & $\begin{array}{l}\text { Lin vd. } \\
(2015)\end{array}$ & $\begin{array}{c}\text { Genetik } \\
\text { algoritma }\end{array}$ & CPLEX \\
\hline $\begin{array}{c}\text { Azaiez ve } \\
\text { Al Sharif } \\
(2005)\end{array}$ & $\begin{array}{l}\text { 0-1 tam sayılı } \\
\text { programlama }\end{array}$ & $\begin{array}{c}\text { ILOG } \\
\text { CPLEX }\end{array}$ & $\begin{array}{l}\text { Thongsanit } \\
\text { vd. (2016) }\end{array}$ & $\begin{array}{c}\text { Hedef } \\
\text { programlama }\end{array}$ & SOLVER \\
\hline $\begin{array}{l}\text { Bard ve } \\
\text { Purnomo } \\
(2005)\end{array}$ & $\begin{array}{l}\text { Kolon üretme } \\
\text { yöntemi/ tam } \\
\text { sayilı } \\
\text { programlama }\end{array}$ & CPLEX/C++ & $\begin{array}{l}\text { Küçük } \\
(2016)\end{array}$ & $\begin{array}{c}\text { Genetik } \\
\text { algoritma }\end{array}$ & MATLAB \\
\hline $\begin{array}{l}\text { Wright vd. } \\
\text { (2006) }\end{array}$ & $\begin{array}{c}\text { Tam sayılı } \\
\text { programlama }\end{array}$ & CPLEX & $\begin{array}{c}\text { Karayel ve } \\
\text { Atmaca } \\
(2017)\end{array}$ & $\begin{array}{c}\text { 0-1 tam } \\
\text { say1l hedef } \\
\text { programlama }\end{array}$ & CPLEX \\
\hline $\begin{array}{l}\text { Trilling vd. } \\
\text { (2006) }\end{array}$ & $\begin{array}{c}\text { Tam sayılı } \\
\text { lineer } \\
\text { programlama }\end{array}$ & ILOG & $\begin{array}{l}\text { Eren vd. } \\
\text { (2017) }\end{array}$ & $\begin{array}{c}\text { Hedef } \\
\text { programlama }\end{array}$ & CPLEX \\
\hline $\begin{array}{l}\text { Çivril } \\
\text { (2009) }\end{array}$ & $\begin{array}{c}\text { Genetik } \\
\text { algoritma }\end{array}$ & $\mathrm{C \#}$ & $\begin{array}{l}\text { Varli vd. } \\
\text { (2017) }\end{array}$ & $\begin{array}{c}\text { Hedef } \\
\text { programlama }\end{array}$ & CPLEX \\
\hline $\begin{array}{c}\text { Maenhout } \\
\text { ve } \\
\text { Vanhoucke } \\
(2011)\end{array}$ & $\begin{array}{l}\text { Evrimsel } \\
\text { algoritma }\end{array}$ & - & $\begin{array}{l}\text { Uslu vd. } \\
\text { (2018) }\end{array}$ & $\begin{array}{c}\text { 0-1 hedef } \\
\text { programlama }\end{array}$ & $\begin{array}{c}\text { ILOG } \\
\text { CPLEX }\end{array}$ \\
\hline $\begin{array}{l}\text { Atmaca vd. } \\
(2012)\end{array}$ & $\begin{array}{l}\text { 0-1 tam sayıli } \\
\text { programlama }\end{array}$ & GAMS & $\begin{array}{c}\text { Eren vd. } \\
\text { (2018) }\end{array}$ & $\begin{array}{c}\text { Hedef } \\
\text { programlama }\end{array}$ & $\begin{array}{l}\text { ILOG } \\
\text { CPLEX }\end{array}$ \\
\hline $\begin{array}{l}\text { Bağ vd. } \\
\text { (2012) }\end{array}$ & $\begin{array}{l}\text { 0-1 tam sayilı } \\
\text { programlama }\end{array}$ & - & $\begin{array}{l}\text { El Adoly } \\
\text { vd. (2018) }\end{array}$ & $\begin{array}{c}\text { Çoklu emtia } \\
\text { ağ akışı } \\
\text { modeli }\end{array}$ & GUROBİ \\
\hline $\begin{array}{c}\text { Büyüközkan } \\
\text { (2012) }\end{array}$ & $\begin{array}{l}\text { Arı kolonisi } \\
\text { algoritması }\end{array}$ & $\begin{array}{c}\text { C\# } \\
\text { GUROBİ }\end{array}$ & $\begin{array}{l}\text { Bayraktar } \\
(2019)\end{array}$ & $\begin{array}{c}\text { Tam say1lı } \\
\text { hedef } \\
\text { programlama }\end{array}$ & GAMS \\
\hline
\end{tabular}


Tablo 1.(devami).

\begin{tabular}{|c|c|c|c|c|c|}
\hline $\begin{array}{l}\text { Burke vd. } \\
\text { (2012) }\end{array}$ & $\begin{array}{c}\text { Pareto } \\
\text { tabanlı } \\
\text { sezgisel } \\
\text { yöntem }\end{array}$ & CPLEX & $\begin{array}{l}\text { Ayan Koç } \\
2019\end{array}$ & $\begin{array}{c}\text { Tavlama } \\
\text { Benzetimi } \\
\text { Algoritması }\end{array}$ & MATLAB \\
\hline $\begin{array}{l}\text { Constantino } \\
\text { vd. (2013) }\end{array}$ & $\begin{array}{l}\text { Sezgisel } \\
\text { yöntem }\end{array}$ & - & Ala (2019) & $\begin{array}{c}\text { Arı kolonisi } \\
\text { Algoritması } \\
\text { ve Genetik } \\
\text { Algoritma }\end{array}$ & CPLEX \\
\hline $\begin{array}{c}\text { Öztürkoğlu } \\
\text { ve Çalışkan } \\
\text { (2014) }\end{array}$ & $\begin{array}{c}\text { Tam sayılı } \\
\text { programlama }\end{array}$ & LINNDO & $\begin{array}{l}\text { Taş ve } \\
\text { Çevik } \\
(2020)\end{array}$ & $\begin{array}{c}\text { Genetik } \\
\text { Algoritma }\end{array}$ & PYTHON \\
\hline $\begin{array}{l}\text { Kim vd. } \\
\text { (2014) }\end{array}$ & $\begin{array}{l}\text { Genetik } \\
\text { algoritma }\end{array}$ & - & $\begin{array}{l}\text { Keskin vd. } \\
\text { (2020) }\end{array}$ & $\begin{array}{c}\text { Karma Tam } \\
\text { sayılı } \\
\text { Doğrusal } \\
\text { Programlama }\end{array}$ & $\mathrm{C} \#$ \\
\hline $\begin{array}{l}\text { Wang vd. } \\
\text { (2014) }\end{array}$ & $\begin{array}{c}0-1 \text { tam } \\
\text { sayılı hedef } \\
\text { programlama }\end{array}$ & LINGO & $\begin{array}{c}\text { Karpuz ve } \\
\text { Batun } \\
(2020) \\
\end{array}$ & $\begin{array}{c}\text { Stokastik } \\
\text { tam sayılı } \\
\text { programlama }\end{array}$ & CPLEX \\
\hline $\begin{array}{l}\text { Legrain vd. } \\
\qquad(2015)\end{array}$ & $\begin{array}{l}\text { Sezgisel } \\
\text { yöntem }\end{array}$ & - & $\begin{array}{l}\text { Karakoç ve } \\
\text { Küçük } \\
(2020)\end{array}$ & $\begin{array}{c}\text { Genetik } \\
\text { algoritma }\end{array}$ & MATLAB \\
\hline $\begin{array}{l}\text { Agyei vd. } \\
(2015)\end{array}$ & $\begin{array}{c}0-1 \text { tam } \\
\text { say1l hedef } \\
\text { programlama }\end{array}$ & LINGO & $\begin{array}{l}\text { Geçici ve } \\
\text { Güler } \\
(2020)\end{array}$ & $\begin{array}{c}\text { Karma tam } \\
\text { sayilı } \\
\text { programlama }\end{array}$ & $\mathrm{CBC}$ \\
\hline
\end{tabular}

\section{Materyal ve yöntem}

Çalışmanın bu kısmında, hemşire çizelgeleme probleminin tanıtımı, problemin çözümü için geliştirilen yöntemler ve önerilen matematiksel programlama model ile ilgili detaylardan bahsedilmiştir.

\subsection{Hedef programlama modeli}

Amaç sayısı fazla olan ve kısıtları kompleks olan problemlerde doğrusal programlama yetersiz kaldığı tespit edilmiştir. Bu durumda hedef programlama devreye girmektedir. Hedef programlama ile soruna çözüm getirilebilir. Hedef programlama modeli amaç fonksiyonunu maksimize ya da minimize etmek yerine uzlaşık çözüme götüren bir modelleme sistemidir. Yani problemin kısitları ile belirlenen hedef veya hedeflerin sapma miktarlarını en küçükleme işlemini gerçekleştirir.

Hedef programlama özellikle iş gücü/personel çizelgeleme gibi kompleks problemlerin çözmek için uygulanır. Başlıca kullanım alanları şu şekildedir: iş gücü planlaması, üretim planlama, sağlık hizmetlerinin planlanması, finansal analiz, personel planlama, akademik planlama, ulaştırma ve lojistik, kuruluş yeri seçimi, kısıtlı kaynakların optimum kullanımı, reklam programlarının kullanılması [39]. 


\subsubsection{Hedef programlamanin yapıst}

Hedef programlama modelinin başlıca altı bileşeni aşağıda verilmiş olup bu altı bileşenin açıklamaları yapılmıştır.

1) Amaç Fonksiyonu: İstenmeyen sapmaları minimize eden fonksiyonun matematiksel gösterimidir.

2) Sapma Değişkeni: Belirlenen amaç ile sonuç arasındaki farktır. Sapma belirlenen amacın altında bir değer aldıysa negatif sapma denir. Eğer sapma değeri belirlenen amacın üzerinde bir değer aldıysa pozitif sapma olarak adlandırılır.

3) Amaç: Karar verecek kişinin kararını ne yönde vereceğini temsil eder. Yani amacın maksimize ya da minimize edilmesidir.

4) Hedef: Amaçlar ile ulaşılması beklenilen rakamsal değerdir.

5) Karar Değişkeni: Karar vericinin belirlediği bilinmeyenler kümesidir.

6) Kısıt: Eşitlik veya eşitsizlik şeklinde karar değişkenlerinden oluşan fonksiyonlardır. Karar değişkenlerinin sağlaması gerekli olan şartlar kümesidir [40].

\subsection{Problemin tanıtımı}

$\mathrm{Bu}$ çalışma bir sağlık kuruluşunun filyasyon ekibi hemşirelerine uygulanmıştır. Sistemde on tane hemşire bulunmaktadır. Her gün 08.00-01.00 saatleri arasında nöbet tutulmaktadır. Nöbetlerde en az üç ve en çok dört hemşire bulundurulmaktadır. Hemşirelerin her biri 1 nöbet gününden sonra 2 gün izin yapmalıdırlar. Her bir hemşire ayda 10 adet nöbet tutmaları gerekmektedir.

$\mathrm{Bu}$ çalışmada filyasyon ekibinde çalışmakta olan hemşirelerin istek ve önerileri dikkate alınarak bir aylık çalışma çizelgesini eşit, dengeli ve adil bir şekilde planlanması amaç edinilmiştir.

\subsection{Hemşire çizelgeleme problemi hedef programlama matematiksel modeli}

Önerilen matematiksel modelin indeks kümeleri, parametreleri, karar değişkenleri, kısıtları ve amaç fonksiyonu aşağıdaki gibi tanımlanmıştır.

\subsubsection{Indislerin ve karar değişkenlerinin tanıtımı}

$\begin{array}{lll}\text { İndisler } & \text { Tanım Kümesi } & \\ i & \text { Gün indisi } & i=\{1,2, \ldots, I\} \\ h & \text { Hemşire indisi } & h=\{1,2, \ldots, H\} \\ I & \text { Gün Sayısı } & \mathrm{I}=30 \\ H & \text { Hemşire Sayıs1 } & \mathrm{H}=10\end{array}$

Karar Değişkenleri

$X_{i, h} \quad h$. hemşire $i$. gün nöbet tutarsa 1; aksi takdirde 0 .

$P_{i, h} \quad h$. hemşire $i$. gün izinli ise 1; aksi takdirde 0 .

$S_{1}^{-} \quad$ Hedef için belirlenen değerden negatif sapma miktarı

$S_{1}^{+} \quad$ Hedef için belirlenen değerden pozitif sapma miktarı 


\subsubsection{Amaç fonksiyonu ve kısıtların tanıtımı}

$\operatorname{Min} Z=S_{1}^{-}+S_{1}^{+}$

$\sum_{h=1}^{10} X_{i, h} \geq 3$

$\forall i$

$\sum_{h=1}^{10} X_{i, h} \leq 4$

$\forall i$

$X_{i, h}+X_{i+1, h} \leq 1$

$\forall i, h$

$X_{i, h}+X_{i+1, h}+X_{i+2, h} \leq 1$

$\forall i, h$

$X_{7,4}=0$

$\forall 7,4$

$X_{10,6}=0$

$\forall 10,6$

$X_{i, h}+P_{i, h}=1$

$\forall_{i, h}$

$\sum_{i=1}^{30} X_{i, h}+S_{1}^{-}-S_{1}^{+}=10 \quad \forall P_{h}$

$X_{i, h}, P_{i, h} \in\{0,1\}$

$S_{1}^{-}, S_{1}^{+} \geq 0$

Geliştirilen hedef programlama modelinde kısıtlar ve amaç fonksiyonu denklemlerinin açıklamaları şu şekildedir: 1. kısıt amaç fonksiyonu kısıtını gösterir. Pozitif ve negatif sapma değerlerinin toplamını minimize etmeyi sağlamıştır. 2. kısıt ise her bir nöbet için gerekli hemşire sayısı en az üç olmalı şartını gerçekleşirmiştir. 3. kısıt ise her bir nöbet için gerekli hemşire sayısı en çok dört olması gerektiğini göstermiştir. 4 . ve 5. kısıt hemşirelerin peş peşe günler nöbet tutmasını engellemiştir. 6. kısıt dördüncü hemşire yedinci gün izinli olması gerektiğini, 7. kısıt ise altıncı hemşire onuncu gün izinli gerektiğini göstermiştir. 8. kısıt her bir hemşirenin nöbette çalıştığını ya da izinli olduğunu göstermiştir. 9. kısıt hedef kısıtıdır. Her hemşirenin bir ay (30 gün) boyunca çalıştığı gün sayısını on gün olacak şekilde birbirine eşitlenmesini sağlamıştır. 10. ve 11. kısıt matematiksel modelde yer alan karar değişkenlerine ait işaret kısıtlarıdır.

Ayrıca sağlık kuruluşundaki sonradan gelişen durumlara göre kısıtlar değişebilir. Hamilelik, süt izni, PCR testi sonucu, ücretsiz izin gibi çok sayıda durumlardan dolayı ekip büyüklüğü değişkenlik gösterecektir. Dolayısıyla kısıtlarda artma söz konusu olabilir. Çalışma mevcut durum göz önünde bulundurularak çözülmüştür.

\section{Hemşire çizelgeleme probleminin çözümü}

Oluşturulan modelin çözümü için Intel Core (TM) i7-CPU 2.60 GHz işlemcisi, 8 GB belleği ile Windows 10 işletim sistemi olan HP marka diz üstü bilgisayar kullanılmıştır. Geliştirilen hedef programlama modeli GAMS 33.2.0 paket programında kodlanarak CPLEX aracı ile bir aylık nöbet çizelgesi oluşturmak için çözümlenmiştir.

GAMS sonuç ekranı incelendiğinde amaç fonksiyonun değeri sıfır çıkmıştır. Yani pozitif ve negatif sapma değerleri sıfır değerini almıştır. Böylece on hemşire bir ay süresince yani 30 gün boyunca on nöbet tutacak şekilde dengeli, eşit sayıda atama yapılmıştır. Tüm kısıtlar sağlanarak nöbet sayısı adil olacak şekilde hemşirelerin nöbet 
çizelgesi oluşturulmuştur. GAMS programı sonuç ekranından elde edilen atama verileri Tablo 2’ye işlenmiştir.

Tablo 2. Hemşirelerin nöbet çizelgesi

\begin{tabular}{|c|c|c|c|c|c|c|c|c|c|c|c|c|c|c|c|c|c|c|c|c|c|}
\hline \multirow{2}{*}{ Gün } & \multicolumn{10}{c|}{ Gün } & \multicolumn{10}{|c|}{ Hemşireler } \\
\hline & $\mathbf{1}$ & $\mathbf{2}$ & $\mathbf{3}$ & $\mathbf{4}$ & $\mathbf{5}$ & $\mathbf{6}$ & $\mathbf{7}$ & $\mathbf{8}$ & $\mathbf{9}$ & $\mathbf{1 0}$ & & $\mathbf{1}$ & $\mathbf{2}$ & $\mathbf{3}$ & $\mathbf{4}$ & $\mathbf{5}$ & $\mathbf{6}$ & $\mathbf{7}$ & $\mathbf{8}$ & $\mathbf{9}$ & $\mathbf{1 0}$ \\
\hline 1 & & 1 & & & & & 1 & & 1 & & 16 & & 1 & & & & & 1 & & 1 & \\
\hline 2 & 1 & & & 1 & 1 & & & 1 & & & 17 & 1 & & & 1 & 1 & & & 1 & & \\
\hline 3 & & & 1 & & & 1 & & & & 1 & 18 & & & 1 & & & 1 & & & & 1 \\
\hline 4 & & 1 & & & & & 1 & & 1 & & 19 & & 1 & & & & & 1 & & 1 & \\
\hline 5 & 1 & & & 1 & 1 & & & 1 & & & 20 & 1 & & & 1 & 1 & & & 1 & & \\
\hline 6 & & & 1 & & & 1 & & & & 1 & 21 & & & 1 & & & 1 & & & & 1 \\
\hline 7 & & 1 & & & & & 1 & & 1 & & 22 & & 1 & & & & & 1 & & 1 & \\
\hline 8 & 1 & & & 1 & 1 & & & 1 & & & 23 & 1 & & & 1 & 1 & & & 1 & & \\
\hline 9 & & & 1 & & & 1 & & & & 1 & 24 & & & 1 & & & 1 & & & & 1 \\
\hline 10 & & 1 & & & & & 1 & & 1 & & 25 & & 1 & & & & & 1 & & 1 & \\
\hline 11 & 1 & & & 1 & 1 & & & 1 & & & 26 & 1 & & & 1 & 1 & & & 1 & & \\
\hline 12 & & & 1 & & & 1 & & & & 1 & 27 & & & 1 & & & 1 & & & & 1 \\
\hline 13 & & 1 & & & & & 1 & & 1 & & 28 & & 1 & & & & & 1 & & 1 & \\
\hline 14 & 1 & & & 1 & 1 & & & 1 & & & 29 & 1 & & & 1 & 1 & & & 1 & & \\
\hline 15 & & & 1 & & & 1 & & & & 1 & 30 & & & 1 & & & 1 & & & & 1 \\
\hline
\end{tabular}

*1 nöbet gününü, boş olan hücreler izin gününü ifade etmektedir.

Oluşturulan tablo amaç fonksiyonunu ve kısıtların tümünü sağlamaktadır. Tabloya dikey bakıldığında her hemşireye ayda toplam 10 nöbet düştüğü görülmektedir. Tabloya yatay bakıldığında her iş gününe minimum 3 maksimum 4 hemşire atandığ 1 görülmektedir. Tablo incelendiğinde her bir hemşirenin 1 nöbet gününden sonra 2 gün izinli olduğu görülmektedir. 4. hemşirenin 7. gün ve 6. hemşirenin 10. gün olacak şekilde istedikleri günlerde izinli olma kısıtı sağlanmıştır.

GAMS programı sonuç ekranı ile oluşurulan tablodan amaç, hedef ve kısıtlarımızın sağlandığını, on hemşirenin bir ay boyunca yani 30 nöbet günü boyunca her hemşire aylık on nöbet tutacak şekilde dengeli ve adil bir şekilde atandığı tabloda görülmektedir.

\section{Sonuçlar ve tartışma}

Sağlık çalışanının uzun süreli çalışma şartlarından dolayı çalışma planları çalışanların memnuniyetleri dikkate alınarak yapılmalıdır. Aynı zamanda hemşire çizelgeleme probleminin yeterli düzeyde çözümlenmesi ve hizmetin aksamaması için her çalışma zamanında yeterli sayıda hemşirenin bulunması, çalışma yükünün dengelenmesi, hizmetin sürekliliği, hasta ve çalışanların memnuniyeti nöbetlerin planlanması faydalı olacaktır.

Günümüzde pandemi koşullarının da etkisi ile hizmet sistemlerinde çizelgelemenin önemi oldukça artmıştır. İş koşullarının ağır ve kompleks yapıda olması sebebiyle çizelgeleme türlerinden biri olan iş gücü çizelgeleme hizmet sektöründe gün geçtikçe 
daha önemli ve daha maliyetli bir hal almaya başlamıştır. İş gücü çizelgeleme çalışanın talebine ve iş kanununa uygun olarak oluşturulan bir çalışma planıdır. Çalışan performans1, memnuniyeti optimum seviyeye ulaştırılmak ve belirlenen amaçların kısıtlardan sapma durumunu minimize etmek amaç edinilmiştir.

Doğrusal programlama çok amaçlı problemlerin çözümünde yetersiz kalabilmaktadır. $\mathrm{Bu}$ nedenle çoğunlukla tercih edilen hedef programlama modeli amaç fonksiyonunu maksimize ya da minimize etmek yerine, var olan kısıtlar eşliğinde, belirlenen hedeflerden sapma miktarlarını minimize ederek uzlaşık çözüm bulmayı sağlar. Hedef programlama özellikle iş gücü çizelgeleme, hemşire çizelgeleme gibi karmaşık problemlerin çözümünde yaygın olarak kullanılır.

$\mathrm{Bu}$ projede sağlık kuruluşunun filyasyon ekibinde çalışan hemşireler için hemşire çizelgeleme problemi ele alınmıştır. Sağlık kuruluşunun hemşireleri planlama prosesinde bulunan hemşire çizelgeleme problemi için kısıtlar göz önünde bulundurularak hedef programlama ile matematiksel model kurulmuştur. $\mathrm{Bu}$ model GAMS 33.2.0 paket programının CPLEX çözücüsü ile çözülerek işgücü sistemi planlanmıştır. Böylece sağlık kuruluşuna ait nöbetler her bir hemşireye eşit sayıda dağıtılıp ve iş yükü adil olacak şekilde dengeli nöbet çizelgesi oluşturulmuştur.

Yeni yapılacak çalışmalarda ekip büyüklüğü, olası durumlar göz önünde bulundurularak model kurgulanıp, gerçek durum ile kıyaslanabilir. Filyasyon ekibinde çalışan diğer sağlık memurları dikkate alınarak hemşire çizelgeleme problemi genişletilebilir. $\mathrm{Bu}$ genişleme sonucunda büyük çözüm uzayı oluşması durumunda meta sezgisel tekniklerden faydalanılabilir.

\section{Kaynaklar}

[1] Ceylan, Z., Arslan, M., Arslan T., Bir hafif raylı ulaşım sisteminde makinist çizelgeleme problemi, Iğdır Üniversitesi Fen Bilimleri Enstitüsü Dergisi, 11, 2, 1027-1039, (2021).

[2] Küçükkoç, İ., Çizelgeleme, http://ikucukkoc.baun.edu.tr/lectures/EMM4129/EMM4129-S1.pdf, (27.09.2018).

[3] Kayacı, M., Yiğit, V., Üretim çizelgeleme problemlerine bulanık yaklaşım, Atatürk Üniversitesi İktisadi ve İdari Bilimler Dergisi, 26, 3-4, (2012).

[4] Yiğit, G., Hedef programlama, https://www.academia.edu/8937644/Hedef_Programlama_Goal_Programming_, (2014).

[5] Güngör, İ., Hemşire görevlendirme ve çizelgeleme sorununa bir model önerisi, Süleyman Demirel Üniversitesi İktisadi ve İdari Bilimler Fakültesi Dergisi, 7, 2, (2002).

[6] Azaiez, M., Al Sharıf, S., A 0-1 goal programming model for nurse scheduling, Proceedings of the 2015 Industrial and Systems Engineering Research Conference, (2005).

[7] Bard, J.F., Purnomo, H.W., Preference scheduling for nurses using column generation, European Journal of Operational Research, 164, 510-534, (2005). 
[8] Trilling, L., Guinet, A., Le Magny, D., Nurse scheduling using integer linear programming and constraint programming, IFAC Proceedings Volumes, (2006).

[9] Wright, P., Bretthauer, K., C'ot'e, M., Reexamining the nurse scheduling problem: staffing ratios and nursing shortages, Decision Sciences, 37, 1, 39-70, (2006).

[10] Çivril, H., Hemşire çizelgeleme probleminin genetik algoritma ile çözümü, Yüksek Lisans Tezi, Süleyman Demirel Üniversitesi, Fen Bilimleri Enstitüsü, Isparta, (2009).

[11] Maenhout, B., Vanhoucke, M., An evolutionary approach for the nurse rerostering problem, Computers \& Operations Research, 38, 10, 1400-1411, (2011).

[12] Atmaca, E., Pehlivan, C., Aydoğdu, C.B., Yakıcı, M., Hemşire çizelgeleme problemi, Erciyes Üniversitesi Fen Bilimleri Enstitüsü Dergisi, 28, 4, 351358, (2012).

[13] Bağ, N., Özdemir, M., Eren, T., 0-1 hedef programlama ve anp yöntemi ile hemşire çizelgeleme problemi çözümü, Uluslararası Mühendislik Araştırma ve Geliştirme Dergisi, 1, 2-6, (2012).

[14] Burke, E.K., Li, J., Qu, R., A pareto-based search methodology for multiobjective nurse scheduling, Annals of Operations Research, (2012).

[15] Büyüközkan, K., Hemşire çizelgeleme probleminin çözümünde arı kolonisi algoritması ve bir sağlık kuruluşunda uygulama, Yüksek Lisans Tezi, (2012).

[16] Constantino, A., Landa-Silva, D., de Melo, EL., de Mendonça, CFX., Rizzato, DB., Romão W., A heuristic algortihm based on multi assignment procedures for nurse scheduling, Annals of Operations Research, 196, 1, 91-109, (2014).

[17] Öztürkoğlu, Y., Çalışkan, F., Hemşire çizelgelemesinde esnek vardiya planlaması ve hastane uygulaması, Dokuz Eylül Ǘniversitesi Sosyal Bilimler Enstitüsü Dergisi, 16, 115-133, (2014).

[18] Kim, S.J., Ko, Y.W., Uhmn, S., Kim, J., Problem, a strategy to 1mprove performance of genetic algorithm for nurse scheduling, International Journal of Software Engineering and Its Applications, 8, 1, 53-62, (2014).

[19] Sheng-Pen, W., Yu-Kuang, H., Zheng-Yun, Z., Nai-Chia, Q., Solving an outpatient nurse scheduling problem by binary goal programming, Journal of Industrial and Production Engineering, 31, 1, 41-50, (2014).

[20] Legrain, A., Bouarab, H., Lahrichi, N., The nurse scheduling problem in reallife, Journal of Medical Systems, 39, 1, 1-11, (2015).

[21] Agye1, W., Obeng-Denteh, W., Andaam, E., Modeling Nurse Scheduling Problem Using 0-1 Goal Programming: A Case Study of Tafo Government Hospital, Kumasi-Ghana, International Journal of Scientific \& Technology Research, 03, 5-10, (2015).

[22] Lin, C., Kang, J., Hsu, T., A memetic algorithm with recovery scheme for nurse preference scheduling, Journal Of Industrial and Production Engineering, (2015).

[23] Küçük, A., Hemşire çizelgeleme problemlerinin genetik algoritmalarla optimizasyonu ve bir uygulama, Yüksek Lisans Tezi, Dokuz Eylül Üniversitesi, Sosyal Bilimler Enstitüsü, İzmir, (2016).

[24] Thongsanit, K., Kantangkul, K., Nithimethirot, T., Nurse's Shift Balancing in Nurse Scheduling Problem, Silpakorn U Science \& Tech J, 10, 43-48, (2015). 
[25] Karayel, S.D., Atmaca, E., Özel bir hastane için hemşire çizelgeleme problemi, Çukurova Üniversitesi İktisadi ve İdari Bilimler Fakültesi Dergisi, 21(2), 112-132, (2017).

[26] Eren, T., Varlı, M., Aktürk, S., Tam gün vardiyalı ve özel izin istekli hemşire çizelgeleme probleminin hedef programlama ile çözümü, Kırıkkale Üniversitesi Sosyal Bilimler Dergisi, 7, 2, 1-16, (2017).

[27] Varlı, E., Ergişi, B., Eren, T., Özel kısıtlı hemşire çizelgeleme problemi: hedef programlama yaklaşımı, Erciyes Üniversitesi İktisadi ve İdari Bilimler Fakültesi, 49, 189-206, (2017).

[28] Geçici, E., Güler, M.G., Hemşire çizelgeleme problemi için bir karar destek sistemi uygulamas1, Pamukkale Üniversitesi Mühendislik Bilimleri Dergisi, 26, 4, 749-757, (2020).

[29] Bayraktar, E., Tam sayılı hedef programlama ve hemşire çizelgeleme problemi için bir uygulama, Yüksek Lisans Tezi, Pamukkale Üniversitesi Sosyal Bilimler Enstitüsü, Pamukkale, (2019).

[30] Küçük, A., Kocakoç D, İ., Hemşire çizelgeleme problemlerinin genetik algoritmalarla optimizasyonu ve bir uygulama, Manisa Celal Bayar Üniversitesi Sosyal Bilimler Dergisi, 19, 203-210, (2021).

[31] Karpuz, E., Batun, S., Nurse scheduling and rescheduling under undercertainty, Hacettepe University Journal of Economics anf Administrative Sciences, 75-95, (2019).

[32] Taş, S.M., Çevik, K.K., Nurse scheduling problem solution using genetic algorithm, 5th International Scientific Research E-Congress, (2020).

[33] Ala, A., Effects of NSGA-II algorithm in compare to beee colony optimization on nurse scheduling problem, International Journal of Applied Optimization Studies, 1-33, (2019).

[34] Keskin, M.E., Kılıç Delice, E., Akkaya, G., Çok bölüm için adil hemşire çizelgeleme, Atatürk Üniversitesi Sosyal Bilimler Dergisi, 1705-1720, (2020).

[35] Uslu, B., Bedir, N., Gür, Ş., Eren, T., 0-1 hedef programlama yöntemi kullanılarak hemşire çizelgeleme probleminin çözümü, Kastamonu Sağlık Akademisi, 148-170, (2018).

[36] Eren, T., Gür, Ş., Turna, K., Varlı, E., Personel yeterliliklerini dikkate alan hemşire çizelgeleme problemi çözümü, Ekonomi, İşletme ve Yönetim Dergisi, 156-175, (2018).

[37] Ayan, Koç, B., Hemşire nöbet çizelgeleme probleminin tavlama benzetimi algoritması ile çözümü, Yüksek Lisans Tezi, Necmettin Erbakan Üniversitesi Fen Bilimleri Enstitüsü, Konya, (2019).

[38] El Adoly, A.A., Gheith, M., Fors, M.N., A new formulation and solution for the nurse scheduling problem: A case study in Egypt, Alexandria Engineering Journal, (2018).

[39] Çakır, E., Hedef programlama, https://www.slideshare.net/cakirengin/hedefprogramlama-presentation, (2008).

[40] Türkoğlu, S.P., Karar vermede hedef programlama yöntemi ve uygulamaları, Osmaniye Korkut Ata Üniversitesi İktisadi ve İdari Bilimler Fakültesi Dergisi, 1, 2, 29-46, (2017). 